\title{
KUALITAS UDARA DALAM RUANG DI DAERAH PARKIR BASEMENT DAN PARKIR UPPERGROUND (STUDI KASUS DI SUPERMARKET SEMARANG)
}

\author{
Haryono S Huboyo*, Titik Istirokhatun, Endro Sutrisno \\ Jurusan Teknik Lingkungan FT. UNDIP, Jl. Prof H. Sudarto SH Tembalang Semarang \\ Email: ${ }^{*}$ huboyo@undip.ac.id
}

\begin{abstract}
Ever increasing building growth in urban areas is limited by land availability. Lack of space in this area lead to build high rise building rather landed building. In this type of building, parking area is built in the basement and or upperground inside the building. Within this enclosed space, indoor air quality might a problem. This study focus to compare emerged pollutants between basement parking area and upperground parking area in supermarket building. The dust sampler, the impinger and the CO monitor were used to measure TSP, $\mathrm{NO}_{2}$ and CO concentrations respectively in these areas during supermarket operations. In the basement area, in particular, the TSP concentrations tend to exceeds $300 \mu \mathrm{g} / \mathrm{m}^{3}$ mainly at weekend period. While for $\mathrm{NO}_{2}$ and $\mathrm{CO}$ concentrations still meet the air quality standard. Based on these findings it seems the main source of pollutants was derived from dust resuspension. Thus, the mitigation measures to reduce this dust resuspension should be emphasized in order to prevent air quality deterioration in the basement parking area.
\end{abstract}

Keywords: air pollutants, enclosed building, parking, weekdays, weekend

\section{PENDAHULUAN}

\section{Latar Belakang}

Berdasar definisi EPA, ada empat elemen yang mempengaruhi sistem pencemaran udara dalam ruang (PUDR) yaitu: sumber yang berasal dari dalam dan luar, sistem ventilasi (HVAC), media pembawa (udara dalam ruang) serta riwayat pekerja yang berdiam di ruang tersebut apakah mempunyai penyakit yang berhubungan dengan PUDR. Secara paparan, pencemaran udara dalam ruang jauh lebih besar dibanding pencemaran luar ruang. Oleh karenanya WHO menyatakan bahwa PUDR seribu kali lebih dapat mencapai paru dibandingkan dengan pencemaran udara luar ruang. Diperkirakan setiap tahun ada sekitar 3 juta kematian akibat polusi udara, 2.8 juta di antaranya akibat PUDR sedangkan sisanya merupakan akibat pencemaran luar ruang (Hidayat, 2012).

Di kota besar dominasi sumber pencemar udara adalah dari kendaraan bermotor. Demikian pula dengan pencemaran udara dalam ruang, dimana beberapa tempat/gedung terdapat sumber pencemar udara dari transportasi. Area parkir indoor merupakan sumber utama pencemaran. Dengan semakin sedikitnya ruang terbuka untuk parkir kendaraan di gedung gedung, maka pilihan lokasi parkir adalah di lantai dasar (basement) dan lantai atas (upper ground). Sayangnya penempatan lokasi parkir ini sedikit sekali yang memperhitungkan kecukupan ventilasinya sehingga nilai air change ratio $(\mathrm{ACH})$ berada dibawah normal sehingga berakibat terakumulasinya polutan. Purwanita (2009) meneliti kandungan timbal di ruangan tertutup sebesar 0.03376 $\mu \mathrm{g} / \mathrm{m}^{3}$. Demikian juga beban cemaran di parkir di basement sudah melebihi baku mutu (Astuti, 2010).

Mall X Semarang merupakan salah satu pusat perbelanjaan terbesar di Kota Semarang. Sebagai salah satu pusat perbelanjaan terbesar juga diikuti dengan besarnya jumlah pengunjung serta kendaraan yang masuk ke Mall X. Menurut pengamatan, areal parkir basement lebih banyak digunakan oleh pengunjung supermarket karena dekat dengan jalan raya. Semakin banyak pengunjung semakin banyak pula jumlah kendaraan yang masuk ke area gedung. 
Huboyo,H. S., Istirokhatun, T., Sutrisno, E.

Kualitas Udara Dalam Ruang Di Daerah Parkir Basement Dan

Mengingat tempat parkir yang dirancang cukup berbeda (lantai dasar dan lantai atas), maka prediksinya lantai atas akan memiliki kecukupan ventilasi karena pengaruh bukaan angin yang cukup besar. Sedangkan bagian basement sangat tergantung dengan ventilasi mekanis untuk menjangkau seluruh area basement.

\section{TUJUAN}

Penelitian ini ditujukan untuk membandingkan besarnya konsentrasi polutan (debu TSP, $\mathrm{NO}_{2}$ dan $\mathrm{CO}$ di perparkiran basement dan upper ground). Luaran dari penelitian ini diharapkan dapat memberikan gambaran bagi pengelola gedung dan masyarakat akan pentingnya sirkulasi udara di perparkiran untuk mencegah terjadinya pencemaran udara dalam ruang.

\section{METODOLOGI}

Area Kajian dan Waktu Sampling

Area penelitian ini dilakukan di area parkir basement dan upper ground di mall $\mathrm{X}$ Semarang. Lokasi titik sampling dapat ditunjukkan pada gambar 1. Waktu pengambilan sampel direpresentasikan oleh hari kerja dan hari libur bulan September 2013.

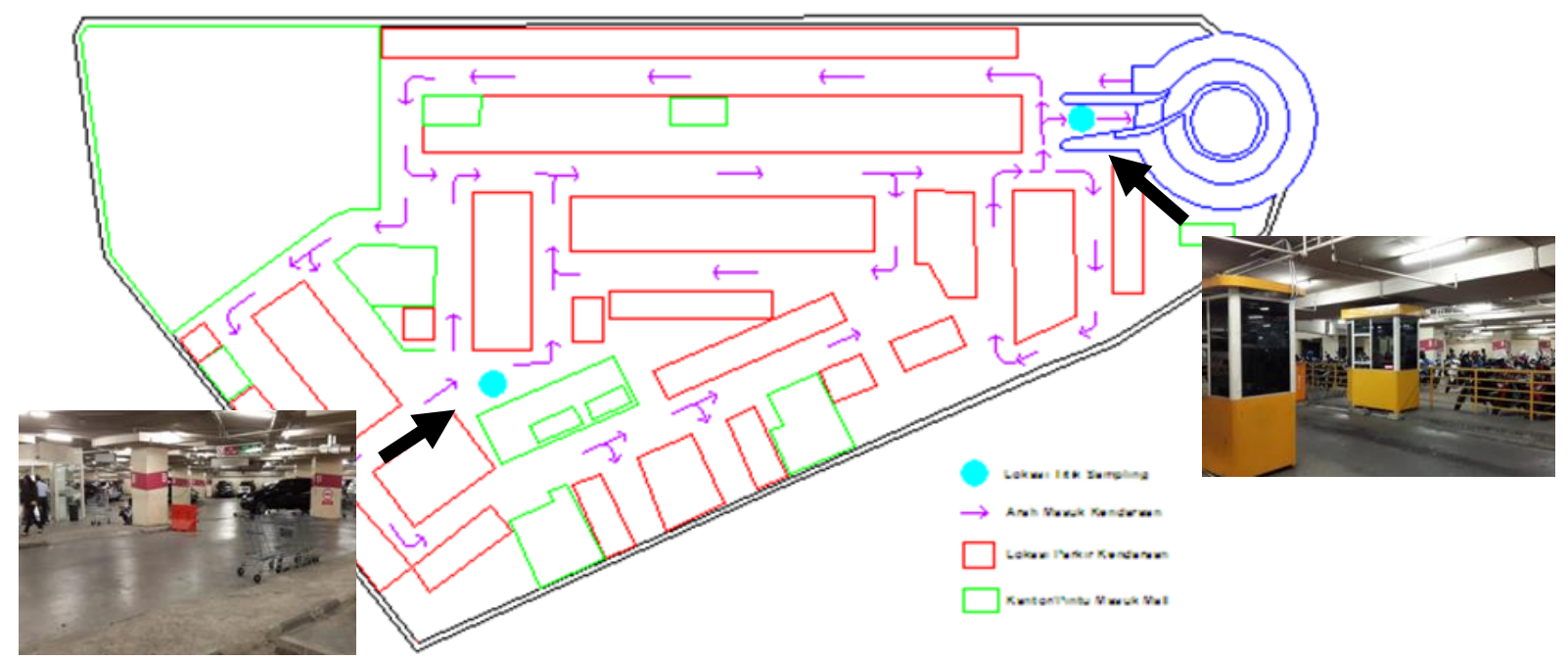

(a)

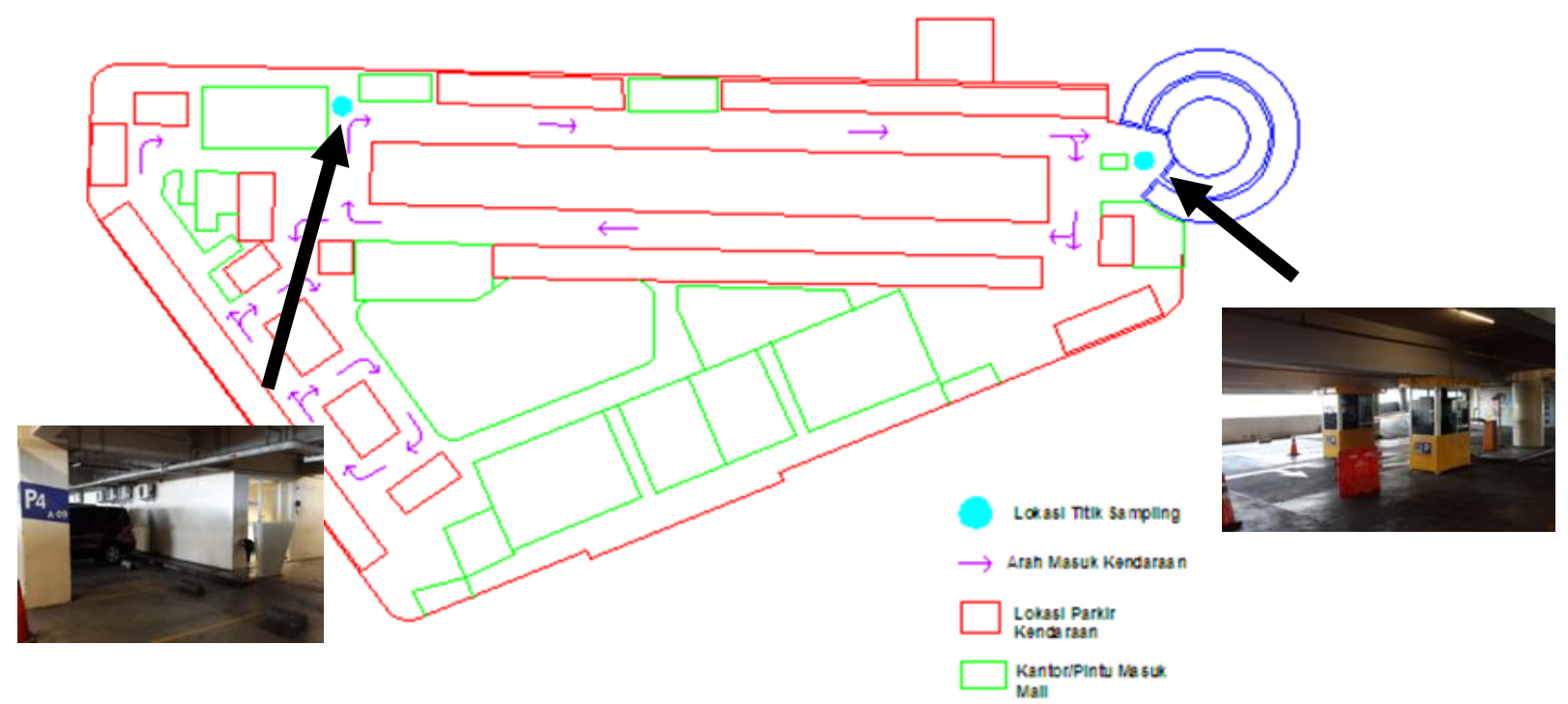

(b)

Gambar 1. Lokasi Sampling (a) di Basement dan (b) di Lantai 4 (Upper ground) 


\section{Metode Pengukuran}

Pengambilan sampling dilakukan di 4 titik yaitu di loket keluar (ticketing) parkir basement, di sekitar pintu masuk mall pada parkir basement, di loket masuk (ticketing) parkir upperground dan di sekitar pintu masuk kantor manajemen di area parkir upper ground. Pengukuran debu TSP dilakukan menggunakan Dust Sampler mengacu pada SNI 19-7119.32005 dengan dust sampler MVS 600 selama 8 jam/hari.Karena baku mutu kualitas udara dalam ruang belum ada maka digunakan baku mutu kualitas udara ambien sebagai penggantinya $\left(230 \mu \mathrm{g} / \mathrm{m}^{3}\right)$. Pengukuran gas $\mathrm{NO}_{2}$ dilakukan selama 1 jam (triplo) per hari, menggunakan Impinger dan dianalisis di laboratorium dengan metode Griess Saltzman.

Pengukuran konsentrasi $\mathrm{CO}$ dengan menggunakan alat $\mathrm{CO}$ meter (Krisbow tipe KW06-292) dilakukan tiap 10 menit dan diratarata kan selama 8 jam per hari. Ada tambahan pengukuran suhu, kelembaban udara dan kecepatan angin menggunakan anemometer. Debu yang terkumpul dianalisis kandungan timbalnya $(\mathrm{Pb})$ dengan AAS (Atomic Absorption Spectrophotometer) mengacu pada SNI 197119.4-2005.

\section{HASIL DAN PEMBAHASAN}

\section{Konsentrasi TSP, $\mathrm{NO}_{2}$ dan $\mathrm{CO}$}

Mall X Semarang terletak di Jl. Pemuda No. 118, Semarang. Pengukuran dilakukan selama 2 minggu dari 3 minggu yang direncanakan karena keterbatasan alat. Pengukuran saat hari kerja (workdays) dilakukan pada hari Senin, Selasa, Rabu. Sedangkan hari libur (weekend) dilakukan pada hari Jumat, Sabtu dan Minggu. Hasil pengukuran (Gambar 2) pada hari libur terlihat jumlah kendaraan yang parkir di mall meningkat ditunjukkan oleh rasio jumlah kendaraan hari kerja dibanding hari libur sebesar 0.7 (basement) dan 0.75 (upperground). Kenaikan jumlah kendaraan pada hari libur berpotensi cemaran yang lebih besar. Kenaikan jumlah kendaraan pada hari libur di basement juga diikuti kenaikan jumlah kendaraan di parkir upperground.

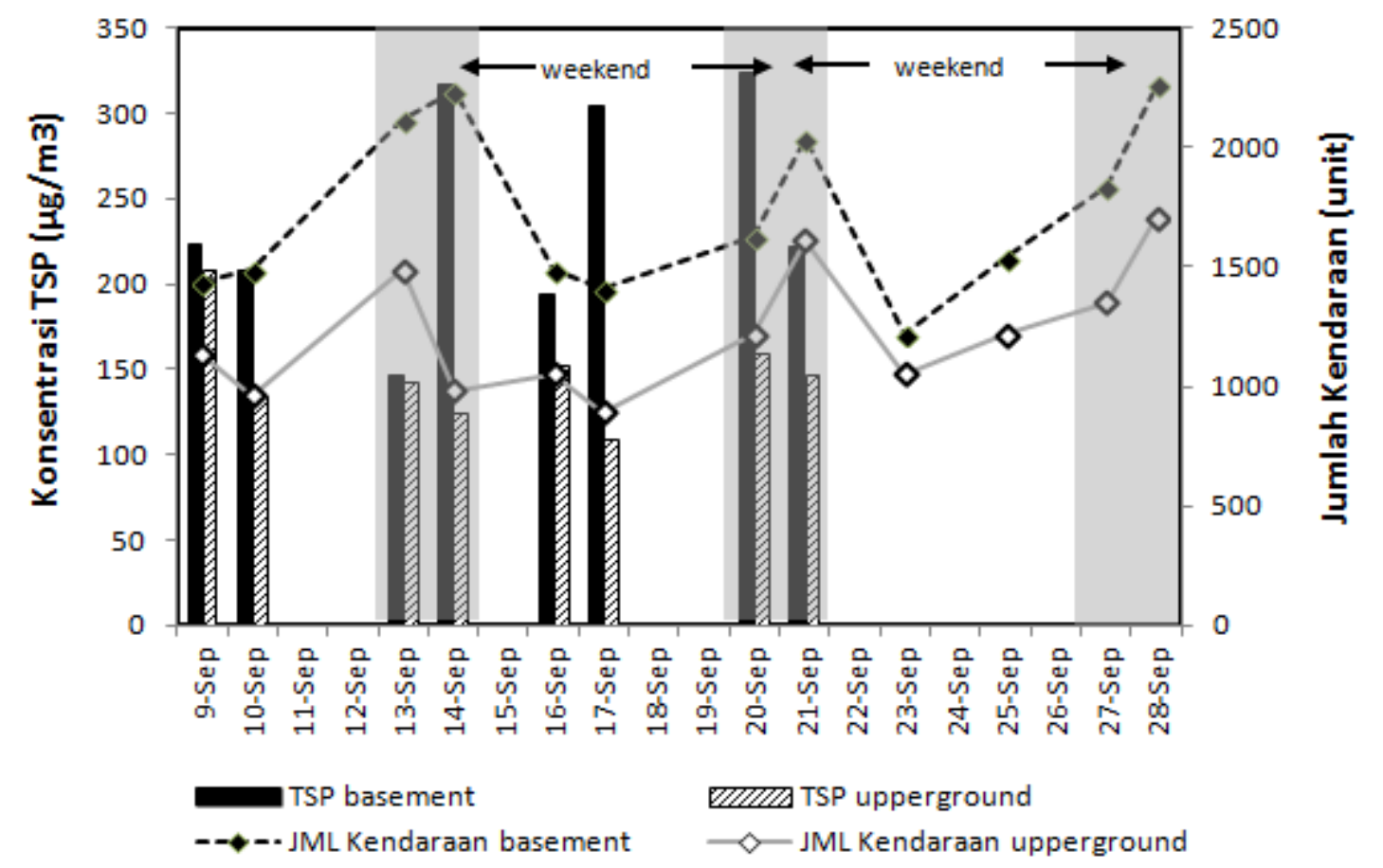

Gambar 2. Konsentrasi TSP di Basement dan Upperground Terhadap Jumlah Kendaraan

Hasil pengukuran di basement, Mall $X$ Semarang menunjukkan pada hari libur rata-rata konsentrasi TSP melebihi baku mutu udara ruang (mencapai $>300 \mu \mathrm{g} / \mathrm{m}^{3}$ ). Peningkatan ini linier dengan peningkatan jumlah kendaraan yang parkir. Namun demikian pada hari kerja (17 September) ada yang melebihi baku mutu dan tidak berkorelasi dengan kenaikan jumlah kendaraan, kemungkinan disebabkan oleh gangguan pengukuran. Rasio rata rata konsentrasi TSP basement dibandingkan konsentrasi upperground sebesar 1.5 (hari kerja) dan 1.8 (hari libur). Hal ini mengindikasikan pekerja/orang yang beraktivitas di ruangan basement akan mengalami resiko terpapar polutan TSP yang lebih besar di banding di ruangan upperground. 


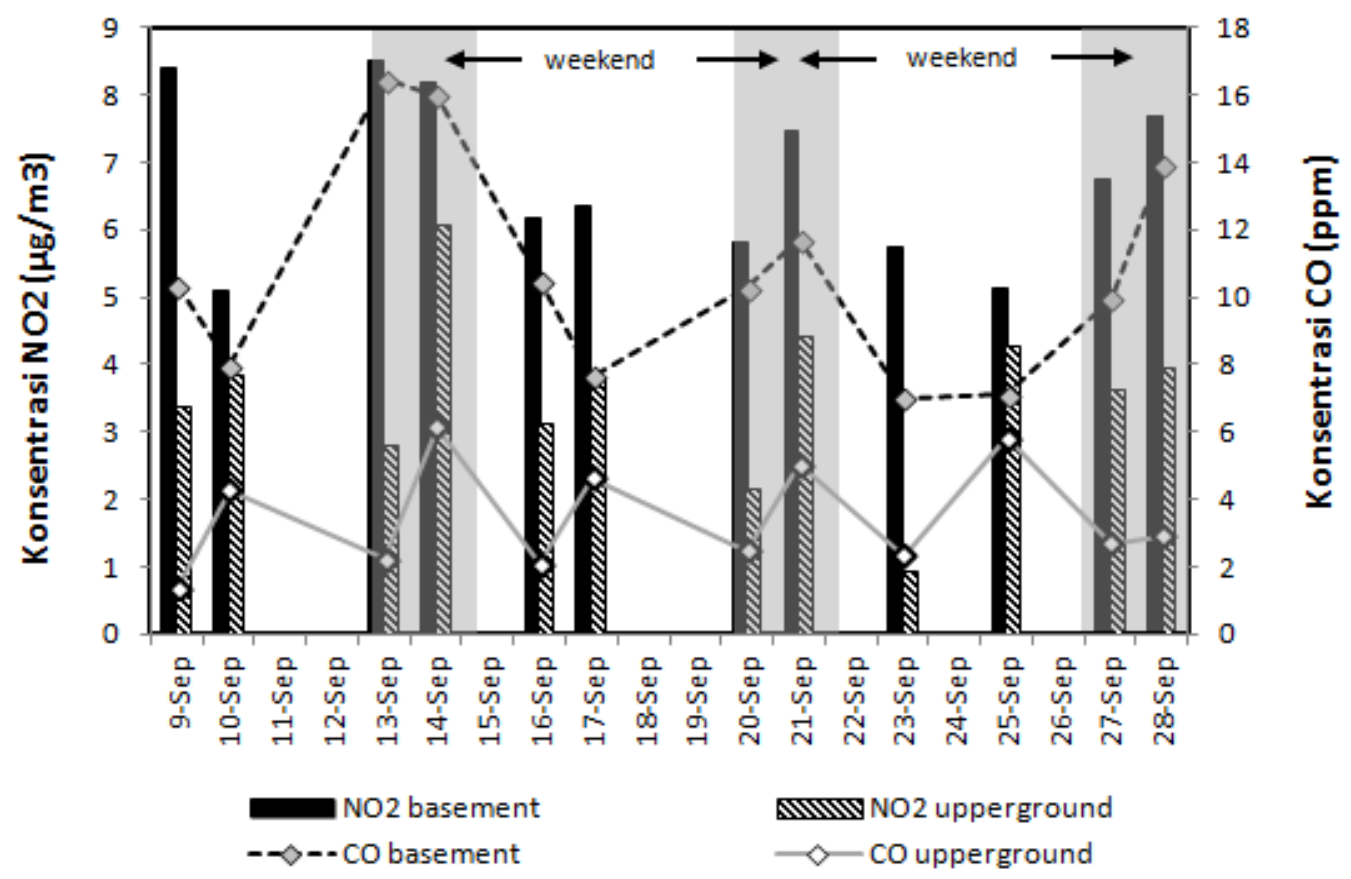

Gambar 3. Konsentrasi $\mathrm{NO}_{2}$ dan $\mathrm{CO}$ di Basement serta Upperground

Konsentrasi $\mathrm{NO}_{2}$ pada hari libur secara konsisten lebih tinggi dibanding pada hari kerja kecuali hari Senin (9 September) walaupun secara kuantitas masih dibawah baku mutu udara ambien untuk $\mathrm{NO}_{2}$ (SK Gubernur Jawa Tengah No. 8 Tahun 2001 yaitu $316 \mu / \mathrm{Nm}^{3}$ ). Konsentrasi $\mathrm{NO}_{2}$ di. Rasio rata rata konsentrasi $\mathrm{NO}_{2}$ di basement dibandingkan konsentrasi upperground cukup sebanding sebesar 1.8 (hari kerja) dan 1.9 (hari libur) hal ini mengindikasikan parameter $\mathrm{NO}_{2}$ tidak tergantung dengan jumlah kendaraan yang parkir. Sementara untuk parameter $\mathrm{CO}$ (semuanya masuk baku mutu sebesar 25 $\mathrm{ppm}$ ), rasio konsentrasi $\mathrm{CO}$ antara basement dan upperground sebesar 2.9 (hari kerja) dan 3.4 (hari libur). Parameter CO cukup konsisten konsentrasi di parkir basement lebih tinggi dibanding di parkir uppaerground. Nilai konsentrasinya juga masih dibawah baku mutu yaitu 25 ppm (Pernakertrans, 2011). Kondisi ini berbeda dengan hasil penelitian Paramita (2006) dimana konsentrasi CO di parkir ruang bawah tanah Jalan Malioboro melebihi baku mutu. Paparan polutan yang terus menerus lebih tinggi di bagian basement dibanding upperground perlu ditanggulangi dengan memperbanyak ventilasi (alami ataupun mekanis) untuk mendapatkan kecukupan pertukaran udara (air change ratio) di suatu ruangan. Kekurangan ventilasi mekanis adalah konsenkuensi biaya yang harus ditambahkan, sementara ventilasi alami akan sedikit mengubah struktur dinding luar namun kehandalannya sangat tergantung kondisi angin diluar.

\section{Konsentrasi Timbal}

Analisis terhadap kandungan timbal $(\mathrm{Pb})$ di filter TSP didapatkan rata-rata konsentrasi timbal seperti dalam Tabel berikut:

Tabel.1 Prosentase (\%) Timbal di TSP

\begin{tabular}{lcc}
\hline \multirow{2}{*}{ Parameter } & \multicolumn{2}{c}{ Parkir } \\
\cline { 2 - 3 } & Basement & Upperground \\
\hline Hari kerja & $0.096 \pm 0.037$ & $0.099 \pm 0.036$ \\
\hline Hari libur & $0.094 \pm 0.028$ & $0.105 \pm 0.024$ \\
\hline
\end{tabular}

Prosentase timbal di TSP tidak banyak berubah dikisaran $0.1 \%$ mengindikasikan tidak ada perubahan di sumber timbalnya. Dalam hal ini sumber kendaraaan bermotor sebagai sumber utama kandungan timbal di udara. Kisaran nilai $\mathrm{Pb}$ di rentang $0.125-$ $0.42 \mu / \mathrm{m}^{3}$ (basement) dan $0.11-0.22 \mu / \mathrm{m}^{3}$ (upperground) masih dibawah baku mutu $\mathrm{Pb}$ di dalam ruang yaitu $2 \mu / \mathrm{m}^{3}$ (Pergub 
DKI, 2008) sehingga dari sisi konsentrasi timbal jumlah kendaraan yang parkir di kedua area parkir tidak menimbulkan dampak kesehatan.

Rendahnya konsentrasi $\mathrm{NO}_{2}, \mathrm{CO}$ dibanding konsentrasi TSP terhadap baku mutu masing masing mengindikasikan bahwa sumber polutan utama adalah resuspended dust (debu terbang) dari lalu lalang kendaraan dan bukan emisi kendaraan secara langsung. Untuk itu mekanisme pembersihan lantai parkir perlu diintensifkan untuk meminimalkan debu terbang. Secara umum, para pegawai yang beraktivias di tempat parkir adalah petugas tiket karcis, pegawai kebersihan dan petugas pengatur parkir. Paparan ke ketiga jenis pekerja itu perlu diminimalkan dengan rotasi dan shift pekerjaan yang lebih intens. Disamping itu, rekayasa ventilasi alami untuk memaksimalkan pertukaran udara ataupun penghilangan polutan di parkir basement juga perlu dilakukan.

\section{KESIMPULAN}

Konsentrasi polutan di area basement secara umum lebih besar dibanding di upperground. Walaupun demikian parameter yang melebihi baku mutu hanyalah debu (TSP).

Kemungkinan sumber polutan terbesar adalah debu terbang (resuspended dust) yang diakibatkan oleh akumulasi debu yang terbang kembali karena lalu lalang kendaraan.

Untuk meminimalkan dampak polutan bagi para pekerja maka perlu diintensifkan pembersihan debu di lantai parkir, memperluas ruang pertukaran udara dan shifting/rotasi pekerja dengan frekuensi yang lebih tinggi.

\section{DAFTAR PUSTAKA}

Astuti, S. K. (2010). Analisis Pembebanan Pencemaran Udara Akibat Emisi Kendaraan Bermotor Pada Parkir Basement Studi Kasus Mall X. Skripsi. Program Studi Teknik Lingkungan Universitas Indonesia Jakarta.

Hidayat, S. (2012). Pengaruh Polusi Udara dalam Ruangan Terhadap Paru. Continuing Medical Education. Universitas Indonesia : Jakarta

Iksan, P. (2008). Analisis Pencemaran Udara O3 dan PM10 Pada Bulan Terbasah dan Bulan Terkering (Studi
Kasus : DKI Jakarta). Fakultas Matematika dan Ilmu Pengetahuan Alam. Bogor : Institut Pertanian Bogor

Peraturan Gubernur Provinsi Daerah Khusus Ibukota Jakarta Nomor 54 Tahun 2008 tentang Baku Mutu Kualitas Udara Dalam Ruang.

Paramitha, N. (2006). Hubungan Volume Kendaraan Bermotor, Suhu, Kelembaban, Arah dan Kecepatan Angin dengan Konsentrasi CO di Ruang Parkir Bawah Tanah (Dalam Ruang) dan di Ruas Jalan (Luar Ruang) (Studi Kasus:Malioboro Mall, Yogyakarta). Laporan Tugas Akhir. Semarang: Program Studi Teknik Lingkungan Diponegoro.

Peraturan Menteri Tenaga Kerja dan Transmigrasi No. 13 Tahun 2011 tentang Nilai Ambang Batas Faktor Fisika Dan Faktor Kimia di Tempat Kerja. Jakarta: Kementerian Tenaga Kerja dan Transmigrasi.

Purwanita, N. (2009). Analisa Resiko Cemaran Pb Terhadap Petugas Parkir di Ruang Parkir Tertutup (Studi Kasus: Plaza Simpang Lima, Semarang). Skripsi. Program Studi Teknik Lingkungan Universitas Diponegoro Semarang.

SNI 19-7119.2-2005. (2005). Cara Uji Kadar Nitrogen Dioksida $\left(\mathrm{NO}_{2}\right)$ dengan metoda Griess Saltzman Menggunakan Spektrofotometer.

SNI 19-7119.4-2005. (2005). Udara Ambien-Bagian 4 : Cara Uji Timbal $(\mathrm{Pb})$ dengan Mtode Destruksi Basah Menggunakan Spektrofotometer Serapan Atom.

Surat Keputusan Gubernur Provinsi Jawa Tengah Nomor 8 Tahun 2001 Tentang Baku Mutu Udara Ambien Provinsi Jawa Tengah 